\title{
Minireview Fusion in the ETS gene family and prostate cancer
}

\author{
SA Narod ${ }^{*, 1}$, A Seth ${ }^{2}$ and $R$ Nam $^{3}$ \\ 'Department of Medicine, Womens College Research Institute, University of Toronto, ON, Canada; ${ }^{2}$ Department of Pathology, Sunnybrook Research \\ Institute, University of Toronto, ON, Canada; ${ }^{3}$ Divisions of Urology and Surgical Oncology, Sunnybrook Health Sciences Centre, Toronto, ON, Canada
}

It has recently been shown that the majority of prostate cancers harbour a chromosomal rearrangement that fuses the gene for an androgen-regulated prostate-specific serine protease, TMPRSS2, with a member of the ETS family of transcription factors, most commonly ERG. These are among the most common genetic alterations in any human solid tumour. This knowledge may provide us with clues to prostate carcinogenesis, and may lead to the development of important molecular-based biomarkers for patients with localised prostate cancer. The most common variant is fusion between the $5^{\prime}$-untranslated region of TMPRSS 2 and the $3^{\prime}$ region of ERG. However, over 20 other fusion variants have now been described (involving over 10 different genes) and the number of variants continues to grow. Fusion products can be identified by several techniques, including FISH, RT-PCR, and expression profiling using exon arrays. The protein products associated with the fusion transcripts have not been characterised, and the phenotypic expression of the various products of gene fusion on prostate cancer histology, or on the clinical course of cancer, are not yet understood. Several early cohort studies suggest that the presence of the TMPRSS2:ERG fusion product is associated with relatively poor cancerspecific survival. Studies that examine how individual variants and their associated phenotypes affect prostate cancer presentation and progression are required.

British Journal of Cancer (2008) 99, 847-85I. doi:I0.1038/sj.bjc.6604558 www.bjcancer.com

(c) 2008 Cancer Research UK

Keywords: prostate cancer; translocation; fusion; ERG; ETS; TMPRSS2

\section{FUSION OF TMPRSS2 AND ETS TRANSCRIPTION FACTOR GENES}

In 2005, Tomlins et al identified and described a small number of fusion transcripts, specific to prostate cancer, that were the consequence of a chromosomal rearrangement involving two genes. One gene, TMPRSS2 (androgen-regulated trans-membrane protease, serine 2), encodes for a serine protease that is secreted by prostate epithelial cells in response to androgen exposure (Afar et $a l, 2001)$. TMPRSS2 was fused to either ERG or ETV1, two members of the ETS family of oncogenes (Tomlins et al, 2005). It had earlier been reported that the ERG gene was the most commonly overexpressed proto-oncogene in prostate cancer (present in about $72 \%$ of cases of prostate cancer) (Petrovics et al, 2005), and Tomlins et al now proposed a mechanism to explain the overexpression. In this landmark paper, they found that both intra-chromosomal and inter-chromosomal genetic rearrangements led to the creation of a fusion transcript called TMPRSS2-ETS. ETS is a family of transcriptional activators and inhibitors. Their activity is regulated by phosphorylation and protein-protein interactions (Seth and Watson, 2005). ERG, ETV1, ETV4, and ETV5 are members of the ETS family. The ERG gene is located on chromosome 21q, ETV1 is located on chromosome 7p, ETV4 on chromosome 17q, and ETV5 on chromosome 3q. Using a novel and powerful bioinformatic technique, they first determined that either ETV1 or ERG (but not both) was commonly overexpressed in prostate cancer cells. Furthermore, overexpression did not usually include all ERG exons - exons 4-7 were

\footnotetext{
*Correspondence: Dr S Narod; E-mail: steven.narod@wchospital.ca
} Received 17 January 2008; revised 2 July 2008; accepted 9 July 2008 overexpressed much more commonly than were exons 1 and 2 . This intriguing observation suggested to them that the gene had somehow been broken - and by sequencing the cDNA products, they confirmed that the $5^{\prime}$ part of the $E R G$ gene had been replaced by the sequence derived from the TMPRSS2 gene. They were able to verify the rearrangement at the DNA level with FISH techniques. Using expression arrays derived from prostate cancer specimens, they confirmed that one of the two ETS oncogenes was overexpressed in $57 \%$ of 167 prostate cancers. They concluded by showing that, in cells which carried either fusion product, expression of the $E R G$ oncogene sequences was under the control of androgen. For example, $\mathrm{VCaP}$ cells, which harbour the fusion product TMPRSS2:ERG, expressed ERG transcript at a level 2000fold greater than LNCAP cells, which do not harbour a fusion product. Because TMPRSS2 is regulated in the prostate by androgens, it was proposed that this gene rearrangement could be a mechanism whereby the ETV1 or ERG oncogenes were overexpressed, leading to prostate cancer.

The TMPRSS2 and ERG genes are about 3 megabases $(\mathrm{mB})$ apart on chromosome 21. In about two-thirds of cases, fusion is the result of the deletion of the intervening DNA sequence, but fusion may also occur by a more complex rearrangement, such as a translocation (Yoshimoto et al, 2006; Tu et al, 2007). The most common fusion is between the $5^{\prime}$-untranslated region of TMPRSS2 and ERG (Perner et al, 2006; Yoshimoto et al, 2006; Tu et al, 2007; Mehra et al, 2007b). The specific points of DNA breakage, and the exons retained in the fusion product, differ between patients. Over 20 TMPRSS2:ERG variants have now been described (Tomlins et al, 2005, 2006; Clark et al, 2007; Liu et al, 2007). A nomenclature has been proposed to describe the variant transcripts, on the basis which exons of the genes are involved (Clark et al, 2007). Most 
variants are the result of a recombination between either exon 1 or exon 2 of TMPRSSR2, and exon 4 of ERG (although exons 2-5 may be involved). The most commonly reported fusion transcript is between exon 1 of TMPRSS 2 and exon 4 of ERG (Clark et al, 2007). This particular rearrangement is designated as T1/E4 according to the nomenclature proposed by Clark et al (2007). This transcript was originally described by Tomlins et al (2005), and in some studies, accounts for up to $86 \%$ of all reported fusions (Wang et al, 2006). Most patients who have been included in clinical and pathologic studies so far carry a variant involving these two genes (Wang et al, 2006; Demichelis et al, 2007; Lapointe et al, 2007; Nam et al, 2007b; Attard et al, 2008).

The number of genes and the variants involved in fusion transcripts continues to grow. Recently, it was found that other members of the ETS gene family (ETV4 and ETV5) are involved in a small proportion of prostate cancer cases (Tomlins et al, 2006; Helgeson et al, 2008). New partners have also been identified on the $5^{\prime}$ side of the translocation. Lapointe et al (2007) identified a fusion product derived from a variant isoform of TMPRSS2, which mapped $4 \mathrm{~kb}$ upstream of the more common start site (Lapointe et al, 2007). One in 10 of the 63 prostate cancer cases in their series expressed this unique isoform. Tomlins et al (2007) and Helgeson et al (2008) implicated other $5^{\prime}$ fusion partners for ETV1, including SLC5A3, HERV-K22q11.23, C15orf21, and HNRPA2B1. SLC5A3 appears to be capable of fusion to ETV5, as well as to ETV1, but not to ERG (Tomlins et al, 2007; Helgeson et al, 2008). Hermans et al (2008) identified two additional fusion partners of ETV4 (kallikrein 2 (KLK2) and calcium-activated nucleotidase 1 (CANT1)) (Hermans et al, 2008).

Considering the new reports, it appears that a member of the ETS family is overexpressed in the majority of prostate cancers and that there may be mechanisms for overexpression other than through gene fusion. In the original paper by Petrovics et al (2005) a high proportion of cancers overexpressed ERG, but the underlying genetic mechanism was not determined. Cai et al (2007) reported that ETV1 was overexpressed in the majority of prostate cancers, but that only the minority of these had evidence of a translocation (Cai et al, 2007). Hermans et al (2006) studied 11 prostate cancer xenografts, some of which exhibited androgendependent growth. In the androgen-dependent cases, the TMPRSS2:ERG fusion transcript was present, and overexpression of the ERG gene was associated with the expression of androgen receptor and PSA. Some androgen-independent cancers were also found to contain the TMPRSS2:ERG fusion transcript, but lacked androgen receptor - it is believed that these tumours have passed through an androgen-dependent phase. They also found two cases of advanced androgen-independent prostate cancer in which other members of the ETS family (specifically FlI-1 and ETV4) were overexpressed due to a mechanism other than gene fusion. Of the $5^{\prime}$ fusion partners identified by Tomlins et al (2007), three (TMPRSS2, SLC5A3, and HERV-K22q11.23) appear to be androgen-responsive and two (C15orf21 and HNRPA2B1) appear to result in constitutive overexpression of ETV1 in the absence of androgen stimulation. In the future, clinical studies should distinguish the course of the disease in cases of cancer with different fusion proteins and the response to androgen ablation treatment.

\section{CHARACTERISATION OF TMPRSS2ERG PROTEIN}

The consequence of the most common gene fusion is to generate a hybrid transcript that attaches the prostate-specific promoter sequence of the TMPRSS2 gene to the ERG oncogene open reading frame (ORF). The proteins sequences have been predicted from the sequence of the fusion ORFs. Clark et al (2007) studied cDNAs prepared from ERG mRNAs isolated from 26 prostate cancers. They reported that of the 14 different fusion transcripts identified from the cDNA sequence, 5 would be predicted to generate premature stop codons and would be unlikely to encode for a functional ERG protein. In most cases, no amino acid sequence derived from TMPRSS2 is integrated in the hybrid ORF, and therefore a fusion protein is not created. In the case of the T1/E2 TMPRSS2:ERG variant, the full-length ERG protein is translated; the other fusion transcripts encode for a truncated protein (Clark et al, 2007).

\section{PREVALENCE OF FUSION PRODUCT AMONG UNSELECTED PROSTATE CANCER CASES}

The presence of a gene fusion product can be determined by measuring the level of RNA expression using RT-PCR, by using FISH (which probes for inappropriate juxtaposition of nonadjacent sequences or the 'break apart' of a single gene to different chromosome locations), or by observing imbalance in the expression of individual exons using array technology. The prevalence rate of fusions among cancer patients depends on the assay used, the volume of the cancer, the number of cancer foci studied, and the number of fusion variants included in the screening panel. The question of prevalence is also complicated by the observation that a single cancer may have different foci that harbour rearrangements involving different genes, or no rearrangment at all (Clark et al, 2007). The field is evolving, but on the whole, these data suggest that $70 \%$ or more of all prostate cancers harbour a fusion product (Hermans et al, 2006; Perner et al, 2006; Soller et al, 2006; Rajput et al, 2007; Tu et al, 2007; Nam et al, 2007a); individual estimates vary from 15\% (Demichelis et al, 2007 ) to $78 \%$ (Soller et al, 2006). As the number of variant species continue to increase and as techniques for measuring them become increasingly diverse and more sensitive, we are likely to find that an even greater proportion of prostate cancer specimens contain one or more fusion variants.

Prostate cancer is often a multifocal disease. Mehra et al (2007a) examined gene fusion status within different tumour foci from 43 patients with multifocal cancers, embedded in a tissue microarray (Mehra et al, 2007a). Of these patients, $70 \%$ had cancers that exhibited a fusion product, but in many cases, different foci from the same tumour carried different fusion products. Surprisingly, $70 \%$ of the cases with fusion were discordant for the specific fusion products. When the largest focus of cancer from each patient was identified, $83 \%$ of samples had a rearrangement. A similar result was obtained by Barry et al (2007), who studied 32 cases of multifocal prostate cancer. Of these cases, $41 \%$ exhibited heterogeneity (Barry et al, 2007). Recently, Clark et al (2007) also found that different cancer foci from a single patient harboured different fusion protiens. In some cases, both ERG and ETV1 were involved in different foci of cancer from the same patient. Thus, heterogeneity of TMPRSS2:ERG gene fusion suggest that the different foci of cancer that arise within a multifocal prostate cancer probably have different origins and represent different malignant clones - this observation also implies that the clinical interpretation of this biomarker is more complex than was originally thought.

\section{PATHOLOGICAL CHARACTERISTICS}

Despite the lack of characterisation of the individual proteins, the phenotypic features of the TMPRSS2:ERG-associated cancers, as a class, have been described. Mosquera et al (2007) studied 120 cases of prostate cancer with the fusion gene, identified from a total of 253 cases (Mosquera et al, 2007). Five histologic features were associated with the presence of gene fusion: the presence of bluetinged mucin, a cribriform growth pattern, macronucleoli, intraductal tumour spread, and signet-ring cell features - these 
features are also associated with an aggressive clinical course of prostate cancer - but neither Gleason grade nor stage was significantly associated with the presence of the fusion gene. Several other studies have compared the characteristic of prostate cancers with and without gene fusion in terms of grade and stage, and PSA level (Perner et al, 2006; Wang et al, 2006; Lapointe et al, 2007; Rajput et al, 2007; Tu et al, 2007). Results to date have been inconsistent, but most studies suggest that the presence of the fusion protein is not correlated with other markers of risk. Rajput et al (2007) found that fusions were less common in low-grade (Gleason 2) prostate cancers (1 of $17 ; 7 \%$ ) than in moderate grade (Gleason $3-5$ ) cancers (35 of $86 ; 41 \%$; $P$-value for difference $=0.02)$. Wang et al (2006) suggested that the T2/E4 variant might be associated with more aggressive disease than other fusion transcripts. This might be the case if the abundance of the oncogene transcript varied between cells with different fusion species, but this hypothesis is not confirmed. TMPRSS2:ERGassociated cancers have also been evaluated from the point of view of gene co-expression. Iljin et al have reviewed expression data derived from 410 different prostate tissue samples. They found that the most common gene that was co-expressed with ERG was histone deacetylase 1 (HDAC 1$)$ and that, in fact, all the ERGpositive prostate cancers in that series were also strongly positive for HDAC (Iljin et al, 2006). This observation suggested to them that anti-HDAC therapies might have a potential therapeutic application for this class of prostate tumours (Li et al, 2005).

\section{CLINICAL SIGNIFICANCE OF TMPRSS2:ERG GENE FUSION}

To date, there are three clearly established prognostic factors for men with localised prostate cancer: histologic grade (measured by the Gleason scoring system, tumour stage, and PSA level at diagnosis. Men with tumours of higher grade (Gleason 8-10), stage (T3-T4), or PSA level (e.g., $>20 \mathrm{ng} \mathrm{ml}^{-1}$ ) experience relatively high rates of progression to metastasis, when compared with men with tumours of lower grade, local stage, or low PSA level. A biomarker will be clinically useful if it allows one to select treatments for individuals; that is if it helps identify subgroups of patients who will, or who will not, benefit from a specific treatment. A patient may not benefit from a treatment because survival is excellent in the absence of treatment, or because the rate of progression is high despite treatment.

In an early study, Petrovics et al (2005) found that ERG sequences were overexpressed in prostate cancer cells relative to adjacent benign prostate cells (at a level of twofold or greater) in approximately $80 \%$ of prostate cancers. In this study, patients with the highest level of expression in their cancer cells (relative to benign tissues) had the best prognosis, and the difference in survival between the groups was highly significant.

The clinical significance of the presence of the TMPRSS2:ERG gene fusion product on prostate cancer presentation and progression is not fully understood, but studies to date suggest that this may be a biomarker of risk. The results of the various studies are inconsistent, possibly because different study designs, different biomarkers, and different end points are used. In general, the case series (Lapointe et al, 2007; Rajput et al, 2007; Tu et al, 2007; Attard et al, 2008) and case-control studies (Perner et al, 2006; Wang et al, 2006) did not identify a significant prognostic effect. Using a case-control approach, Wang et al (2006) examined 119 patients for fusion status. They found a significant correlation with tumour stage, but not with early recurrence. Lapointe et al (2007) found modest correlations between stage and grade and the presence of the fusion product, but the sample size was small ( $n=63$ cases $)$ and neither association was statistically significant.

In contrast to the early study of ERG gene expression by Petrovics et al (2005), three recent cohort studies that evaluated the presence of the fusion protein per se on patient outcome have found the translocation to be an adverse prognostic factor. Two of these studies included patients undergoing watchful waiting. These authors sought to determine whether patients who do not harbour a fusion product might be candidates for watchful waiting. Currently, it is estimated that up to $30 \%$ prostate cancer patients lack the fusion protein, and therefore the potential exists to avoid the morbidity associated with anti-androgen therapy or with surgery for a significant proportion of patients. However, it should also be remembered that more than half of prostate cancer patients have cancers that harbour a fusion product, and we expect that many patients with clinically localised disease will be cured of cancer by prostatectomy, even if the fusion product is present.

Demichelis et al (2007) followed 111 patients undergoing watchful waiting for localised prostate cancer (Demichelis et al, 2007). Patients with the gene fusion had a 2.7 -fold increase in prostate cancer-specific mortality, when compared with patients without fusion. However, $23 \%$ of 94 patients without the fusion protein experienced metastatic prostate cancer after 12 years of observation, when compared with $53 \%$ of 17 patients with fusion. Although the difference was statistically significant $(P<0.01)$, a recurrence risk of $23 \%$ is not sufficiently low to endorse watchful waiting as an alternative to surgery. In a similar study, Attard et al (2008) studied 445 patients under watchful waiting. Fusion analysis was conducted on prostate specimens embedded in a tissue microarray using FISH. In this study, patients without the fusion transcript had a good survival experience (90\% survival at 10 years). Attard et al (2008) refined their study by sub-dividing patients with fusion transcripts into three categories: (1) those with retained $5^{\prime}$ and $3^{\prime} E R G$ DNA sequences; (2) those with one retained copy of $3^{\prime} E R G$ sequence but no retained $5^{\prime} E R G$ sequence; and (3) those with two copies of the retained $3^{\prime} E R G$ sequence (i.e., homozygous or duplicated) but no retained $5^{\prime} E R G$ sequence. The third group was noteworthy for its poor prognosis; after 8 years of follow-up, patients in this group were six times more likely to die from prostate cancer than those with no TMPRSS2:ERG gene fusion (hazard ratio $=6.1,95 \%$ CI: $3.3-11.1$, $P<0.0001)$. Only $25 \%$ of patients in this class were alive at 8 years. The frequency of gene rearrangements in the Attard et al (2008) study was $30 \%$, when compared with only $15 \%$ in the study by Demichelis et al (2007). It may be that the Demichelis group used a less sensitive assay to screen for the presence of the fusion gene, or that a number of variant transcripts went undetected, and that this resulted in misclassification and attenuation of the true effect (however, in a later study from the same group, the low prevalence of rearrangements was confirmed). The patients in the Demichelis study were from Sweden, and it is possible that the prevalence of the fusion protein varies with ethnic group. It remains to be proven that patients who lack fusion genes may be candidates for watchful waiting. Future studies might benefit from including additional markers of risk in the prognostic model, including grade, stage, PSA level, ethnic group, and the presence of one or more markers of genetic susceptibility, such as the recently defined cluster of markers on chromosome 8q24 (Amundadottir et al, 2006; Yeager et al, 2007; Zheng et al, 2007).

In a prospective cohort study, Nam et al (2007b) examined the effect of the most common fusion variant (T1/E4) on disease recurrence (defined by a rising PSA level after surgery) among 165 patients who underwent surgery for localised prostate cancer (Nam et al, 2007b). This particular gene fusion was present in $49 \%$ of patients, and $26 \%$ of the patients developed biochemical disease recurrence. Patients with fusion had a much higher rate of recurrence ( $54 \%$ at 5 years) than those without fusion (8\%). Fusion status did not correlate with PSA, grade, or stage. After adjusting for PSA, grade, and stage, the hazard ratio for recurrence was 8.5 (95\% CI: $3.6-20.6, P<0.0001$ ). This study implies that this biomarker may be an independent prognostic factor of disease recurrence. However, although all patients who die of prostate 
cancer experience biochemical recurrence before death, only a minority of patients with biochemical recurrence succumb to prostate cancer. It is important that large studies of prostatectomy patients be conducted with longer follow-up and that additional end points include distal recurrence and prostate-specific mortality. The T1/E4 variant is the most common of TMPRSS2:ERG gene fusions and is the best studied; it is not yet known if other variants are associated with prostate cancer prognosis to the same extent. Furthermore, it is not clear why the results of the three cohort studies (which examined the presence of the fusion protein) had results that differed dramatically from those of Petrovics et al (2005) who examined the overexpression of ERG. Petrovics et al measured overexpression in cancer tissues relative to benign prostate, and it is possible that expression levels in the surrounding stroma are clinically relevant as well. In an ideal study, one would perform both assays on a single group of patients.

The TMPRSS2:ERG gene fusion is specific for prostate cancer, and the ability to identify this DNA rearrangement could be used as a screening test for prostate cancer in serum, prostatic fluid, or in urine. One study has been conducted on DNA specimens isolated from urine from men known to have prostate cancer with a gene rearrangement (Hessels et al, 2007). The sensitivity of the urine test was only $37 \%$ and the specificity was $93 \%$. It is possible that future assays will have comparatively better sensitivity or that the presence of the fusion gene in urine could supplement a panel of markers in a screening setting.

\section{CONCLUSIONS}

In conclusion, the discovery by Tomlins et al in 2005 of a frequent genetic rearrangement in prostate cancers has changed our conception about the role of chromosomal rearrangements in the aetiologies of common solid tumours. In the short time since this discovery, several authors have confirmed the importance of this genetic fusion, and have expanded the class of fusion genes greatly. It now appears that these are among the most frequent recurrent rearrangements in cancer. The consequence of the various fusion transcripts is the overexpression of a member of the ETS family of oncogenes, initially under the control of androgen and the androgen receptor, but androgen dependence may be lost in advanced disease. It now appears that activation of this pathway may be central to prostate carcinogenesis, but the clinical implication of the various fusion products has not been worked out. It is hoped that this discovery will quickly lead to treatments tailored to patients in different risk classes, and possibly to a screening test, and ultimately it is hoped that the ETS family oncogenes will be molecular targets for novel therapies.

\section{REFERENCES}

Afar DE, Vivanco I, Hubert RS, Kuo J, Chen E, Saffran DC, Raitano AB, Jakobovits A (2001) Catalytic cleavage of the androgen-regulated TMPRSS2 protease results in its secretion by prostate and prostate cancer epithelia. Cancer Res 61: 1686-1692

Amundadottir LT, Sulem P, Gudmundsson J, Helgason A, Baker A, Agnarsson BA, Sigurdsson A, Benediktsdottir KR, Cazier JB, Sainz J, Jakobsdottir M, Kostic J, Magnusdottir DN, Ghosh S, Agnarsson K, Birgisdottir B, Le Roux L, Olafsdottir A, Blondal T, Andresdottir M, Gretarsdottir OS, Bergthorsson JT, Gudbjartsson D, Gylfason A, Thorleifsson G, Manolescu A, Kristjansson K, Geirsson G, Isaksson H, Douglas J, Johansson JE, Balter K, Wiklund F, Montie JE, Yu X, Suarez BK, Ober C, Cooney KA, Gronberg H, Catalona WJ, Einarsson GV, Barkardottir RB, Gulcher JR, Kong A, Thorsteinsdottir U, Stefansson K (2006) A common variant associated with prostate cancer in European and African populations. Nat Genet 38: 652-658

Attard G, Clark J, Ambroisine L, Fisher G, Kovacs G, Flohr P, Berney D, Foster CS, Fletcher A, Gerald WL, Moller H, Reuter V, De Bono JS, Scardino P, Cuzick J, Cooper CS (2008) Duplication of the fusion of TMPRSS 2 to ERG sequences identifies fatal human prostate cancer. Oncogene 27: 253-263

Barry M, Perner S, Demichelis F, Rubin MA (2007) TMPRSS2 -ERG fusion heterogeneity in multifocal prostate cancer: clinical and biologic implications. Urology 70: 630-633

Cai C, Hsieh CL, Omwancha J, Zheng Z, Chen SY, Baert JL, Shemshedini L (2007) ETV1 is a novel androgen receptor-regulated gene that mediates prostate cancer cell invasion. Mol Endocrinol 21: 1835-1846

Clark J, Merson S, Jhavar S, Flohr P, Edwards S, Foster CS, Eeles R, Martin FL, Phillips DH, Crundwell M, Christmas T, Thompson A, Fisher C, Kovacs G, Cooper CS (2007) Diversity of TMPRSS2-ERG fusion transcripts in the human prostate. Oncogene 26: 2667-2673

Demichelis F, Fall K, Perner S, Andren O, Schmidt F, Setlur SR, Hoshida Y, Mosquera JM, Pawitan Y, Lee C, Adami HO, Mucci LA, Kantoff PW, Andersson SO, Chinnaiyan AM, Johansson JE, Rubin MA (2007) TMPRSS2:ERG gene fusion associated with lethal prostate cancer in a watchful waiting cohort. Oncogene 26: 4596-4599

Helgeson BE, Tomlins SA, Shah N, Laxman B, Cao Q, Prensner JR, Cao X, Singla N, Montie JE, Varambally S, Mehra R, Chinnaiyan AM (2008) Characterization of TMPRSS2:ETV5 and SLC45A3:ETV5 gene fusions in prostate cancer. Cancer Res 68: 73-80

Hermans KG, Bressers AA, van der Korput HA, Dits NF, Jenster G, Trapman J (2008) Two unique novel prostate-specific and androgenregulated fusion partners of ETV4 in prostate cancer. Cancer Res 68: $3094-3098$

Hermans KG, van Marion R, van Dekken H, Jenster G, van Weerden WM Trapman J (2006) TMPRSS2:ERG fusion by translocation or interstitial deletion is highly relevant in androgen-dependent prostate cancer, but is bypassed in late-stage androgen receptor-negative prostate cancer. Cancer Res 66: $10658-10663$

Hessels D, Smit FP, Verhaegh GW, Witjes JA, Cornel EB, Schalken JA (2007) Detection of TMPRSS2-ERG fusion transcripts and prostate cancer antigen 3 in urinary sediments may improve diagnosis of prostate cancer. Clin Cancer Res 13: 5103-5108

Iljin K, Wolf M, Edgren H, Gupta S, Kilpinen S, Skotheim RI, Peltola M, Smit F, Verhaegh G, Schalken J, Nees M, Kallioniemi O (2006) TMPRSS2 fusions with oncogenic ETS factors in prostate cancer involve unbalanced genomic rearrangements and are associated with HDAC1 and epigenetic reprogramming. Cancer Res 66: $10242-10246$

Lapointe J, Kim YH, Miller MA, Li C, Kaygusuz G, van de Rijn M, Huntsman DG, Brooks JD, Pollack JR (2007) A variant TMPRSS2 isoform and ERG fusion product in prostate cancer with implications for molecular diagnosis. Mod Pathol 20: $467-473$

Li LC, Carroll PR, Dahiya R (2005) Epigenetic changes in prostate cancer: implication for diagnosis and treatment. J Natl Cancer Inst 97: 103-115

Liu W, Ewing CM, Chang BL, Li T, Sun J, Turner AR, Dimitrov L, Zhu Y, Sun J, Kim JW, Zheng SL, Isaacs WB, Xu J (2007) Multiple genomic alterations on $21 \mathrm{q} 22$ predict various TMPRSS2/ERG fusion transcripts in human prostate cancers. Genes Chromosomes Cancer 46(11): $972-980$

Mehra R, Han B, Tomlins SA, Wang L, Menon A, Wasco MJ, Shen R, Montie JE, Chinnaiyan AM, Shah RB (2007a) Heterogeneity of TMPRSS2 gene rearrangements in multifocal prostate adenocarcinoma: molecular evidence for an independent group of diseases. Cancer Res 67: $7991-7995$

Mehra R, Tomlins SA, Shen R, Nadeem O, Wang L, Wei JT, Pienta KJ, Ghosh D, Rubin MA, Chinnaiyan AM, Shah RB (2007b) Comprehensive assessment of TMPRSS2 and ETS family gene aberrations in clinically localized prostate cancer. Mod Pathol 20: 538-544

Mosquera JM, Perner S, Demichelis F, Kim R, Hofer M, Mertz K, Paris P, Simko J, Collins C, Bismar T, Chinnaiyan A, Rubin M (2007) Morphological features of TMPRSS2-ERG gene fusion prostate cancer. J Pathol 212: 91 - 101

Nam RK, Sugar L, Wang Z, Yang W, Kitching R, Klotz LH, Venkateswaran V, Narod SA, Seth A (2007a) Expression of TMPRSS2 ERG gene fusion in prostate cancer cells is an important prognostic factor for cancer progression. Cancer Biol Ther 6: e1-e6

Nam RK, Sugar L, Yang W, Srivastava S, Klotz LH, Yang L-H, Stanimirovic A, Encioiu E, Loblaw DA, Trachtenberg J, Narod SA, Seth A (2007b) 
Expression of the TMPRSS2 erg fusion gene predicts cancer recurrence after surgery for localized prostate cancer. Br J Cancer 97: 1690-1695

Perner S, Demichelis F, Beroukhim R, Schmidt FH, Mosquera JM, Setlur S, Tchinda J, Tomlins SA, Hofer MD, Pienta KG, Kuefer R, Vessella R, Sun XW, Meyerson M, Lee C, Sellers WR, Chinnaiyan AM, Rubin MA (2006) TMPRSS2:ERG fusion-associated deletions provide insight into the heterogeneity of prostate cancer. Cancer Res 66: 8337-8341

Petrovics G, Liu A, Shaheduzzaman S, Furasato B, Sun C, Chen Y, Nau M, Ravindranath L, Chen Y, Dobi A, Srikantan V, Sesterhenn IA, McLeod DG, Vahey M, Moul JW, Srivastava S (2005) Frequent overexpression of ETS-related gene-1 (ERG1) in prostate cancer transcriptome. Oncogene 24: $3847-3852$

Rajput AB, Miller MA, De Luca A, Boyd N, Leung S, Hurtado-Coll A, Fazli L, Jones EC, Palmer JB, Gleave ME, Cox ME, Huntsman DG (2007) Frequency of the TMPRSS2:ERG gene fusion is increased in moderate to poorly differentiated prostate cancers. J Clin Pathol 60: $1238-1243$

Seth A, Watson DK (2005) ETS transcription factors and their emerging roles in human cancer. Eur J Cancer 41: 2462-2478

Soller MJ, Isaksson M, Elfving P, Soller W, Lundgren R, Panagopoulos I (2006) Confirmation of the high frequency of the TMPRSS2/ERG fusion gene in prostate cancer. Genes Chromosomes Cancer 45: 717-719

Tomlins SA, Laxman B, Dhanasekaran SM, Helgeson BE, Cao X, Morris DS, Menon A, Jing X, Cao Q, Han B, Yu J, Wang L, Montie JE, Rubin MA, Pienta KJ, Roulston D, Shah RB, Varambally S, Mehra R, Chinnaiyan AM (2007) Distinct classes of chromosomal rearrangements create oncogenic ETS gene fusions in prostate cancer. Nature 448: 595-599

Tomlins SA, Mehra R, Rhodes DR, Smith LR, Roulston D, Helgeson BE Cao X, Wei JT, Rubin MA, Shah RB, Chinnaiyan AM (2006) TMPRSS2:ETV4 gene fusions define a third molecular subtype of prostate cancer. Cancer Res 66: 3396-3400
Tomlins SA, Rhodes DR, Perner S, Dhanasekaran SM, Mehra R, Sun XW, Varambally S, Cao X, Tchinda J, Kuefer R, Lee C, Montie JE, Shah RB, Pienta KJ, Rubin MA, Chinnaiyan AM (2005) Recurrent fusion of TMPRSS2 and ETS transcription factor genes in prostate cancer. Science 310: $644-648$

Tu JJ, Rohan S, Kao J, Kitabayashi N, Mathew S, Chen YT (2007) Gene fusions between TMPRSS2 and ETS family genes in prostate cancer: frequency and transcript variant analysis by RT-PCR and FISH on paraffin-embedded tissues. Mod Pathol 20: 921-928

Wang J, Cai Y, Ren C, Ittmann M (2006) Expression of variant TMPRSS2/ ERG fusion messenger RNAs is associated with aggressive prostate cancer. Cancer Res 66: 8347-8351

Yeager M, Orr N, Hayes RB, Jacobs KB, Kraft P, Wacholder S, Minichiello MJ, Fearnhead P, Yu K, Chatterjee N, Wang Z, Welch R, Staats BJ, Calle EE, Feigelson HS, Thun MJ, Rodriguez C, Albanes D, Virtamo J, Weinstein S, Schumacher FR, Giovannucci E, Willett WC, Cancel-Tassin G, Cussenot O, Valeri A, Andriole GL, Gelmann EP, Tucker M, Gerhard DS, Fraumeni Jr JF, Hoover R, Hunter DJ, Chanock SJ, Thomas G (2007) Genome-wide association study of prostate cancer identifies a second risk locus at 8q24. Nat Genet 39: 645-649

Yoshimoto M, Joshua AM, Chilton-Macneill S, Bayani J, Selvarajah S, Evans AJ, Zielenska M, Squire JA (2006) Three-color FISH analysis of TMPRSS2/ERG fusions in prostate cancer indicates that genomic microdeletion of chromosome 21 is associated with rearrangement. Neoplasia 8: $465-469$

Zheng SL, Sun J, Cheng Y, Li G, Hsu FC, Zhu Y, Chang BL, Liu W, Kim JW, Turner AR, Gielzak M, Yan G, Isaacs SD, Wiley KE, Sauvageot J, Chen HS, Gurganus R, Mangold LA, Trock BJ, Gronberg H, Duggan D, Carpten JD, Partin AW, Walsh PC, Xu J, Isaacs WB (2007) Association between two unlinked loci at $8 \mathrm{q} 24$ and prostate cancer risk among European Americans. J Natl Cancer Inst 99: 1525-1533 